\title{
POLYACRYLAMIDE AMENDMENT FOR EROSION AND RUNOFF CONTROL ON SOILS OF DIFFERING CHARACTERISTICS
}

\author{
Sang Soo Lee \\ Dr. Clark J. Gantzer, Dissertation Advisor
}

\begin{abstract}
The use of anionic polyacrylamide (PAM) as a soil amendment is an emerging conservation practice. However, guidelines have not been developed with considerations of soil properties and topographic characteristics. The objectives of these studies were to evaluate the effects of PAM, gypsum, or their combination for four dependent variables of time to initial runoff (TRO), cumulative runoff (RO), and cumulative sediment loss (SL) on different soil materials with selected slopes. Each soil material was packed to a bulk density of $1.3 \mathrm{Mg} \mathrm{m}^{-3}\left(81 \mathrm{lb} \mathrm{ft}^{-3}\right)$ in soil test beds subjected to a 61-mm h $\mathrm{h}^{-1}$ (2.4-in $\mathrm{hr}^{-}$ ${ }^{1}$ ) simulated rainfall with a kinetic energy (KE) of $1.5 \mathrm{~kJ} \mathrm{~m}^{-2} \mathrm{~h}^{-1}\left(103 \mathrm{ft} \mathrm{lb} \mathrm{ft}^{-2} \mathrm{hr}^{-1}\right.$ ) for 62 min. Differences in TRO, RO, and SL for soils, amendments, and slopes were all significant, as were their two-way interactions $(p<0.01)$. Tested soil amendments had varied responses on TRO, RO, and SL within soils. For reducing SL, a high level of PAM had better performance at a steep slope compared to a low level of PAM or $\leq 40 \%$ slope. Generally, the applications of PAM amendment were not effective in reducing RO, but increased TRO. Differing amendment performance for different soils and slopes make it necessary to continue to understand the soil-PAM bonding mechanisms.
\end{abstract}

